\title{
CONDUCTIVE HEAT TRANSFER PREDICTION OF PLAIN SOCKS IN WET STATE
}

\author{
Tariq Mansoor ${ }^{1, *}$, Lubos Hes ${ }^{1}$, Amany Khalil', Jiri Militky ${ }^{1}$, Maros Tunak ${ }^{1}$, Vladimir Bajzik ${ }^{1}$, Yordan Kyosev $^{2}$ \\ 1 Faculty of Textile Engineering, Technical University of Liberec, Czech Republic \\ 2 Institute for Textile Machinery and Textile High-Performance Materials Technology (ITM), Technical University, Dresden, Germany \\ *Corresponding author. E-mail: taheembava1@gmail.com
}

\begin{abstract}
:
In this study, an algebraic model and its experimental verification was carried out to investigate the effect of moisture content on the heat loss that takes place due to conduction of sock fabrics. The results show that increasing moisture content in the studied socks caused a significant increase in their conductive heat loss. Plain knitted socks with different fiber composition were wetted to a saturated level, and then their moisture content was reduced stepwise. When achieving the required moisture content, the socks samples were characterized by the Alambeta testing instrument for heat transfer. Three different existing modified mathematical models for the thermal conductivity of wet fabrics were used for predicting thermal resistance of socks under wet conditions. The results from both ways are in very good agreement for all the socks at a 95\% confidence level. In the above-mentioned models, the prediction of thermal resistance presents newly a combined effect of the real filling coefficient and thermal conductivity of the so-called "wet" polymers instead of dry polymers. With these modifications, the used models predicted the thermal resistance at different moisture levels. Predicted thermal resistance is converted into heat transfer (due to conduction) with a significantly high coefficient of correlation.
\end{abstract}

\section{Keywords:}

Heat transfer, mathematical modeling, plain socks, moisture content, filling coefficient, volume porosity

\section{Introduction}

Heat transfer by conduction mostly depends on fiber's thermal conductivity, volume, orientation to the heat flow direction, and fabric construction [1, 2]. Thermal conductivity of the fabrics can be evaluated in different ways: experimental method, analytical solution method, and numerical method [3]. Most of the studies on thermal conductivity/thermal resistance in the wet state to date are experimental and reported that there was an increase in thermal conduction consequent to increasing the moisture content [4-8]. This study will provide a quantitative prediction of the insulation loss with the addition of water in socks. Sock insulation is linked to the material thickness and trapped air (porosity) in between the fibers. The increase in the insulation of footwear may not be obvious for the shoes only. It depends on the sock's insulation as well because low insulation shoes can get more insulation comparatively from socks than shoes. Footwear insulation is a vital feature for feet warmth; on the other hand, the sweat generation due to the motion of subjects can strongly affect the foot temperatures. Mostly the cold feet sensation is associated with low skin temperatures due to sweating [9]. Even well-insulated footwear will start feeling cold on wetting. Socks are made of fabrics where the absorbed moisture can strongly influence their thermal comfort properties, since a human foot could generate up to $30-50 \mathrm{~g}$ of sweat per hour in a hot environment $[10,11]$. At a high physical activity, it could be $30 \mathrm{~g} \cdot \mathrm{h}^{-1}$ even in the cold environment [12]. For a single foot, the most recent study reports the range $\left(10.3 \pm 3.6 \mathrm{~g} \cdot \mathrm{h}^{-1}\right)$ with shoes compared to an uncovered foot $\left(12.6 \pm 3.7 \mathrm{~g} \cdot \mathrm{h}^{-1}\right)$ [13]. Owing to these high sweat rates, the heat loss may substantially increase. Prolonged damp and cold conditions can cause injuries similar to a trench foot. The trench foot, however, does not require a freezing temperature; it can occur at hot temperatures as well [14]. Many studies on thermal resistance prediction through empirical models are available in the literature; these models are specifically volume fractions and based on their respective thermal conductivities. Numerical approaches can deal with uneven profiles, solid/ liquid/gas phases, different forms of heat transfer, number of boundary conditions, and uneven material properties. Numerical methods also have the potential to attain the utmost precision [15]. However, these methods are intrinsically more complex and awkward; further, under certain conditions, plain methods demonstrated to be more precise for much less stab [16]. Some researchers employed artificial neural networks (ANN) models for thermal resistance [17, 18] and thermal conductivity [19] predictions. In most of the studies, thermal resistance is predicted by statistical models [20]. Some researchers have predicted the thermal conductivity of wet fabrics with mathematical approaches. Schuhmeister [21] developed a relationship to calculate the thermal conductivity of the mixture of air and fiber with the following assumptions:

a) Fibers are distributed homogeneously in all directions;

b) One-third of fibers were placed in parallel; and 
c) Two-thirds of fibers were placed in series or perpendicular to the heat flow.

Later, many researchers followed the footprints of Schuhmeister by changing the ratio of fibers placed in series to those placed in parallel $[22,23]$. Recently, Militky considered placing $50 \%$ fibers in series and $50 \%$ in parallel to the heat flow [24]. R. S. Hollies and Herman Bogaty have suggested a parallel combination for measuring the effective thermal conductivity of moistening fabric by combining the volume fraction and thermal conductivity of water and polymer [25]. Mangat presented a number of mathematical models for thermal resistance (wet state) in the series and in parallel combinations of air, fiber, and water resistance. His predictions are in good correlation with the experiments $[26,27]$. The problem with Mangat's models is the assumption made concerning the filling coefficient or porosity as constant components. However, varying the moisture levels can result in changes because water has a different density. Although his second assumption that the air is replaced by water is theoretically correct, but he did not quantify it. Hes, R. S. Hollies, and Herman Bogaty have ignored the series arrangement in their suggested models. It will predict the lower thermal resistance as heat will conduct along with the thickness of the fabric. S. Naka et al. suggested a theoretical approach for thermal conductivity prediction but they did not use it for calculations. They also involved the warp and weft fabric thickness in their suggested model. The model used by Dias and Delkumburewatte is a three parameters series model, which is a very simple approach; yet, they ignored the parallel conduction part so it can predict higher thermal resistance. Presently, Mansoor et al. [28, 29] have modified Maxwell-Eucken- (ME-)2, Schuhmeister, and Militky models by combining the water and fiber filling coefficient for predicting the thermal resistance of wet socks. We have used the same approach for the prediction of thermal resistance and heat transfer through conduction in this study. The general aims of this study are as follows:

- To predict the heat transfer of wet socks through conduction by using the Mansoor et al. modified models.

- To study conductive heat transfer (predicted/experimental) in the extended state (controlled moisture content in \%) for simulating a real extension and minimizing the effect of the dimensional changes.

- To ascertain the volume porosity of socks with and without extension in the model.

- To ascertain the volume porosity and pore size distribution of socks by X-ray micro-tomography (MCT) scanning without extension.

By combining the fiber and water filling coefficients approach, below three models have predicted the reasonable thermal resistance for socks that are in agreement with the experimental results. These models are discussed in the forthcoming sections.

\subsection{ME-2-modified model}

Maxwell introduced the two-phase concept for the determination of electrical conductivity [30]. Later on, Eucken used the same analogy for the thermal conductivity evaluation [31]. Brailsford and Major (Eq. [1]) have modified the ME models for thermal conductivity of a three-phase mixture by assuming first phase as continuous while other two as dispersed [32].

$$
\lambda=\frac{\lambda_{0} v_{0}+\lambda_{1} v_{1} \frac{s \lambda_{0}}{\left(2 \lambda_{0}+\lambda_{1}\right)}+\lambda_{2} v_{2} \frac{s \lambda_{0}}{\left(2 \lambda_{0}+\lambda_{2}\right)}}{v_{0}+v_{1} \frac{s \lambda_{0}}{\left(2 \lambda_{0}+\lambda_{1}\right)}+v_{2} \frac{s \lambda_{0}}{\left(2 \lambda_{0}+\lambda_{2}\right)}}
$$

Later on Eq. (1) was generalized by Wang et al. [33] as shown by Eq. (2).

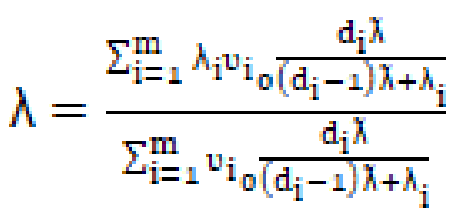

ME's Eq. (3) is obtained by assuming air and wet polymer as disperse and continuous phases, respectively, for Eq. (2). ME model (Eq. 3) can be used to describe an effective thermal conductivity of a two-component material with simple physical structures. Equation (3) represents a two-component system for effective thermal conductivity, based on volume fraction and respective. Many effective thermal conductivity models require the naming of continuous and dispersed phases. In materials with exterior porosity, individual solid particles are surrounded by a gaseous matrix, and hence the gaseous component forms the continuous phase and the solid component forms the dispersed phase [34]. For external porosity, they are considered as continuous and dispersed phases, respectively, as follows.

$$
\lambda_{\text {fab }}=\frac{\lambda_{\mathrm{a}} \mathrm{F}_{\mathrm{a}}+\lambda_{\text {wet polymer }} \mathrm{F}_{\text {wet polymer }} \frac{\mathrm{s} \lambda_{\mathrm{a}}}{2 \lambda_{\mathrm{a}}+\lambda_{\text {wet polymer }}}}{\mathrm{F}_{\mathrm{a}}+\mathrm{F}_{\text {wet polymer }} \frac{\mathrm{s} \lambda_{\mathrm{a}}}{2 \lambda_{\mathrm{a}}+\lambda_{\text {wet polymer }}}}
$$

$\mathrm{F}_{\text {wet polymer }}$ and $\lambda_{\text {wet polymer }}$ are calculated as per Eqs (13)(15).

\subsection{Schuhmeister-modified model}

Schuhmeister's equation, given by Eq. (4), summarized the relationship between the thermal conductivity of fabric and the fabric structural parameters by an empirical equation [21].

$$
\begin{aligned}
& \lambda_{\text {fab }}=0.67 \times \lambda_{s}+0.33 \times \lambda_{\mathrm{p}} \\
& \text { Where } \lambda_{\mathrm{s}}=\frac{\lambda_{\text {wet polymer }} \times \lambda_{\mathrm{a}}}{\lambda_{\text {wet polymer }} \mathrm{F}_{\mathrm{a}}+\lambda_{\mathrm{a}} \mathrm{F}_{\text {wet polymer }}} \\
& \text { and } \lambda_{\mathrm{p}}=\mathrm{F}_{\text {wet polymer }} \lambda_{\text {wet polymer }}+\mathrm{F}_{\mathrm{a}} \lambda_{\mathrm{a}}
\end{aligned}
$$

where $\lambda_{\text {fab }}$ is the thermal conductivity of fabric, $\lambda_{\text {wet polymer }}$ is the conductivity of wet fibers, $\lambda_{\mathrm{a}}$ is the conductivity of air, 
$F_{\text {wet polymer }}$ is the filling coefficient of the solid fiber, and $F_{a}$ is the filling coefficient of air in the insulation.

\subsection{Militky-modified model}

Militky's equation, given by Eq. (7), summarized the relationship between the thermal conductivity of fabric by an empirical equation [24].

$\lambda_{\text {fab }}=\left(\frac{\lambda_{s}+\lambda_{p}}{2}\right)$

where $\lambda_{s}$ and $\lambda_{p}$ are calculated using Eqs (5) and (6), resnertively, $\lambda_{\mathrm{fab}}$ is the thermal conductivity of fabric, $\lambda_{\text {wet polymer }}$ is the conductivity of wet fibers, $\lambda_{a}$ is the conductivity of air, $F_{\text {wet polymer }}$ is the filling coefficient of the solid fiber, and $\mathrm{F}_{\mathrm{a}}$ is the filling coefficient of air in the insulation.

\section{Materials and methods}

\subsection{Socks samples}

All the plain (single jersey) socks samples as shown in (Table 1 and Figures 1 and 2) were knitted on the same machine (Lonati Goal GL544S, 144Needles, Diameter 4", 4Feed) settings by varying the main yarns to get the homogeneous samples with respect to specs and stretches for contrast comparison. "The

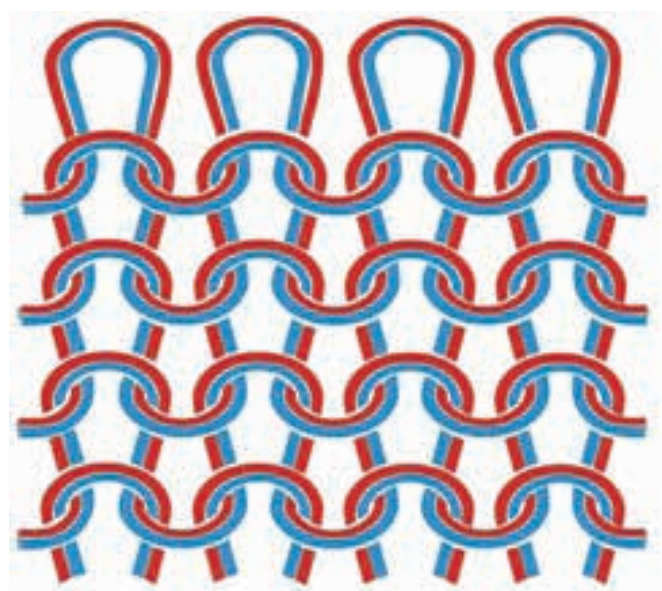

Figure 1. Knitting style of plain (single jersey) sock construction.

yarn running at the surface of the sock is called the main yarn and the plaiting yarn (generally spandex covered polyamide or polyester filament yarn) runs inside the fabric providing stretch, elasticity, comfort and shape to the sock" [35, 36]. After knitting, all the samples were processed for washing in the same machine bath followed by tumble drying and boarding.

Images for all the samples are taken using a camera (ProgResCT3) attached to a macro- scope (NAVITAR) with the lights and stand (HAISER Germany) from front and backside of the

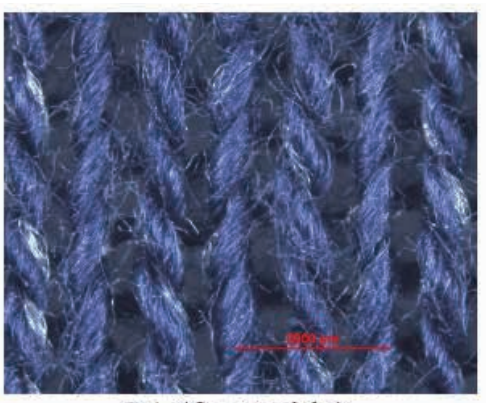

P1 (front side)

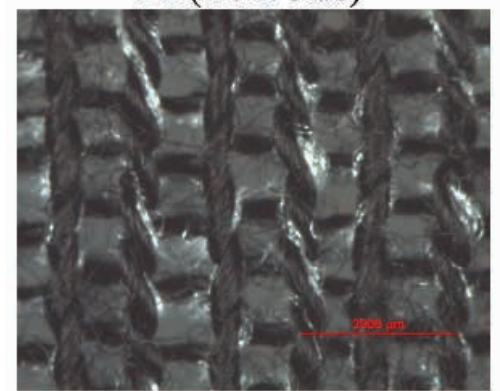

P2 (front side)

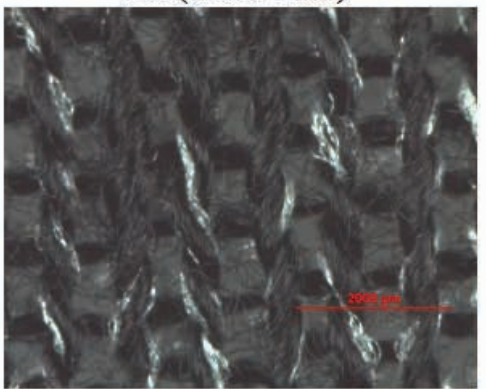

P3 (front side)

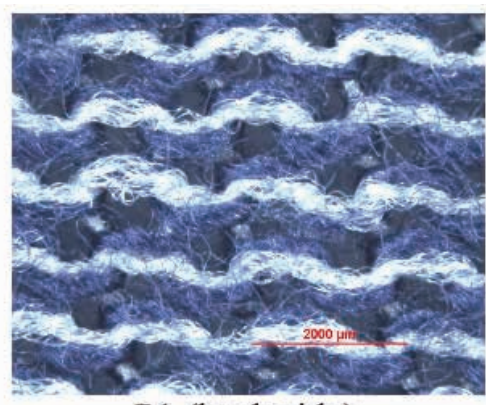

P1 (back side)

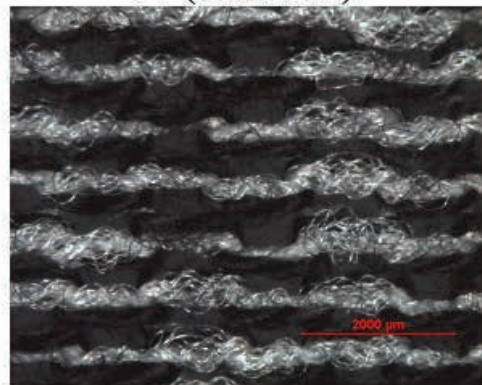

P2 (back side)

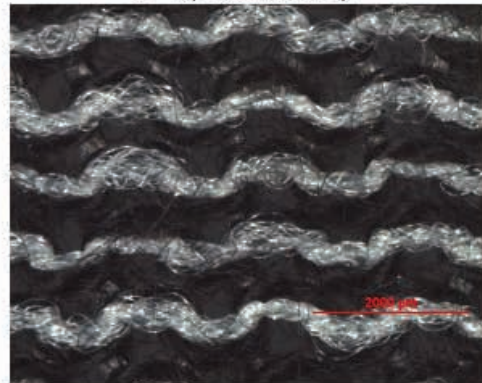

P3 (back side)

Figure 2. Sock images by macroscopic camera (with extension). 
Table 1. Sock samples specifications.

\begin{tabular}{|c|c|c|c|c|c|}
\hline $\begin{array}{l}\text { Main yarn nominal } \\
\text { count }\end{array}$ & Plaiting yarn & Fiber composition (\%) & $\begin{array}{c}\text { GSM } \\
\left(g^{-2}\right)\end{array}$ & $\begin{array}{l}\text { Thickness } \\
\text { (mm) }\end{array}$ & $\begin{array}{l}\text { Sock } \\
\text { codes }\end{array}$ \\
\hline $\begin{array}{c}29.525 / 1 \text { tex } 100 \% \\
\text { Cotton spun yarn }\end{array}$ & \multirow{3}{*}{$\begin{array}{l}2.22 / 8.33 / 36 / 1 \text { tex Polyester } \\
\text { air covered Elastane (91:9)\% }\end{array}$} & $\begin{array}{l}\text { Cotton } 80 \% \text {, Polyester } \\
18.20 \% \text {, Elastane } 1.8 \%\end{array}$ & 129.88 & 0.95 & $\mathrm{P} 1$ \\
\hline $\begin{array}{l}29.525 / 1 \text { tex } 100 \% \\
\text { Viscose Spun yarn }\end{array}$ & & $\begin{array}{c}\text { Viscose } 81.08 \% \text {, } \\
\text { Polyester } 17.22 \% \text {, } \\
\text { Elastane } 1.70 \% \\
\end{array}$ & 130.44 & 0.90 & $\mathrm{P} 2$ \\
\hline $\begin{array}{l}29.525 / 1 \text { tex } 100 \% \\
\text { Spun Polyester }\end{array}$ & & $\begin{array}{l}\text { Polyester } 98.38 \% \text {, } \\
\text { Elastane } 1.62 \%\end{array}$ & 125.70 & 0.95 & P3 \\
\hline
\end{tabular}

socks under extension (Figure 2). Main and plaited yarns could be observed from front side and back side of the socks easily. Main yarn is more prominent from front side, except that some of the plaited yarn loops could be seen over the main yarn for samples P1, P2, and P3 due to contrast of color. Plaiting yarn along with the main yarn could be easily distinguished from the back side of these samples.

\subsection{Volume socks porosity by model}

Sock's structure is important due to several advantages. Physically, it presents properties of comfort such as high elasticity, conformity with the shape of the body, softer hands feel, and others. In general, heat and mass transmission rate is dependent mainly on the fabric's geometrical parameters, namely, thickness and porosity [37]. Porosity $(\varepsilon)$ is the volumetric ratio of the pores accessible by total volume [38]. The porosity of the fabrics can be calculated by air permeability, image processing, and geometrical modeling approaches [39]. Volume porosity of the socks was determined according to Eq. (8) $[40,41]$.

Porosity $(\varepsilon) \%=\left(\frac{\rho_{0}-\rho}{\rho_{0}}\right) \times 100$

where $\rho_{0}$ is fiber density $\left(\mathrm{kg} \cdot \mathrm{m}^{-3}\right)$ and $\rho$ is fabric density $\left(\mathrm{kg} \cdot \mathrm{m}^{-3}\right)$.

\subsection{D porosity of socks by MCT scanning}

3D porosity of the socks was investigated by using an x-ray computed MCT SKYSCAN 1272 system. In this system, radiation is converted into an electrical signal between the $x$-ray source and the detector when the specimen revolves on a vertical axis. 2D images are taken in several steps during this rotary motion. Reconstruction software generates a 3D model of the actual specimen from these images [42]. The following are the common settings for all the tested samples: image pixel size, $-3.0 \mu \mathrm{m}$; lower grey threshold, -33 ; upper grey threshold, -255 ; rotation step, $-0.2^{\circ}$; rotation degrees, $-180^{\circ}$; frame averaging, -3 ; exposure, $-672 \mathrm{~ms}$; voltage source, $-50 \mathrm{kV}$; source current, -200 uA.

\subsection{Sample preparation for testing}

For the extension simulation, the socks were loaded on a dummy leg (Salzmann MST Switzerland) [43] of medium size $(24 \mathrm{~cm})$ as per specification of the standard method (RALGZ-387/1). Then worn socks are marked as per the testing template. After unloading, the socks were extended to the marked circle with the help of an embroidery hoop as shown in Figure 3. Sock samples were wet to the saturated level (100\% moisture content) by BS EN ISO 105-X12 standard test method. The established technique for preparing a wet fabric of the known oven-dry fabric weight is used and thus the fabric is thoroughly wetted in distilled water. The wet pick-up is brought to $100 \pm 0.5 \%$ by putting wet testing fabric on a blotting paper. The evaporation of the moisture content below the specified

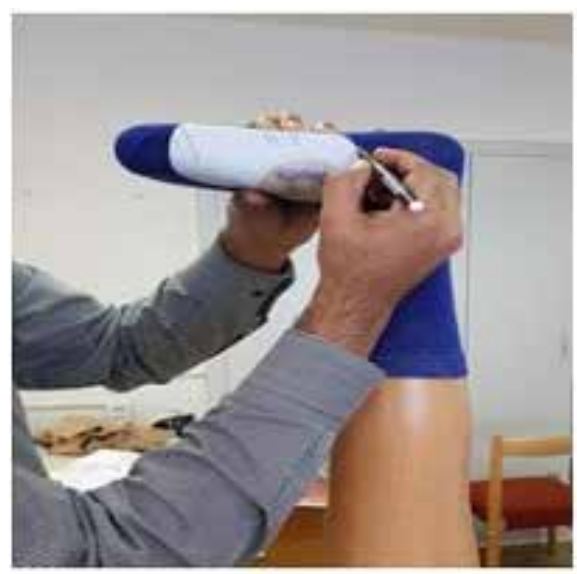

(a)

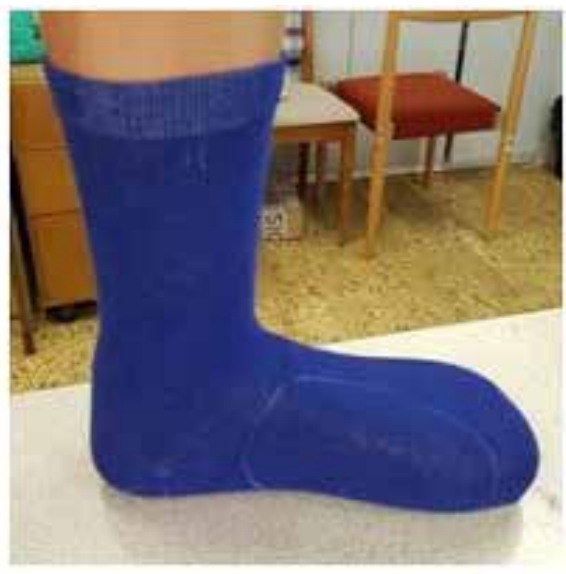

(b)

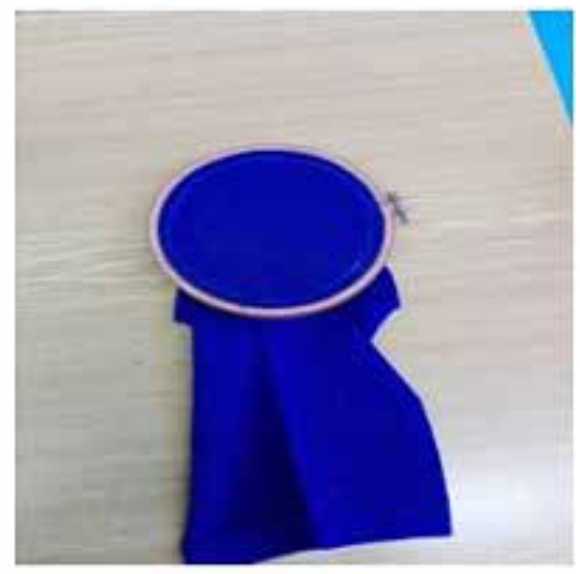

(c)

Figure 3. Schematic illustration of (a) Circle marking, (b) Socks loading on dummy foot, and (c) Embroidery hoop, respectively. 
level was avoided by using polyethylene bags. Further, we tested again for the above-mentioned tests under extension at different moisture levels.

\subsection{Testing equipment/methods}

A testing method was selected for this research as per the condition of worn socks and limitations of the manikins. Socks worn inside shoes show 1st-order boundary conditions and constant, different temperatures on both surfaces of the fabric (such as Alambeta). Socks were worn (calf area) partly under 3rd-order boundary conditions; conduction inside = convection outside (thermal foot model, permetest). The condition is more clearly illustrated in Figure 4. Furthermore, short testing time (almost keeping the specific moisture content) distinguish the Alambeta from other skin models and manikins. So, Alambeta was selected especially for wet testing.

\subsection{Alambeta (equivalent to ISO 8301)}

The thermal resistance (Rct) of the developed samples was measured by Alambeta tester [44], which rapidly measures both steady-state and transient-state thermal properties. This instrument simulates the heat flow $\mathrm{q}\left(\mathrm{W} \cdot \mathrm{m}^{-2}\right)$ from the human skin to the fabric during a short initial contact in the absence of body movement and external wind flow. When the two bodies are brought into ideal contact, the time course of temperatures is determined by solving the known one-dimensional partial differential equation Eq. (9) according to the relation subsisting between them.

$\frac{\partial \mathrm{T}}{\partial \mathrm{t}}=\mathrm{a} \frac{\partial^{2} \mathrm{~T}}{\partial \mathrm{x}^{2}}$

where $a$ is the thermal diffusivity which can be calculated from Eq. (10).

$\mathrm{a}=\frac{\lambda}{\rho \mathrm{c}}(10)$

The measuring head drops down, touches the fabrics, the heat flow levels are processed, and the thermo-physical properties of the measured specimens are evaluated [5]. The measurement lasts for several minutes only. Thus, reliable measurements on wet fabrics are possible, since the sample moisture during the measurement is almost constant. As mentioned earlier, socks are worn inside the shoes under 1st-order boundary conditions, and Alambeta-testing corresponded well with the use of socks inside a shoe (boundary conditions of first-order). Thermal resistance assessed using the Alambeta tester, which

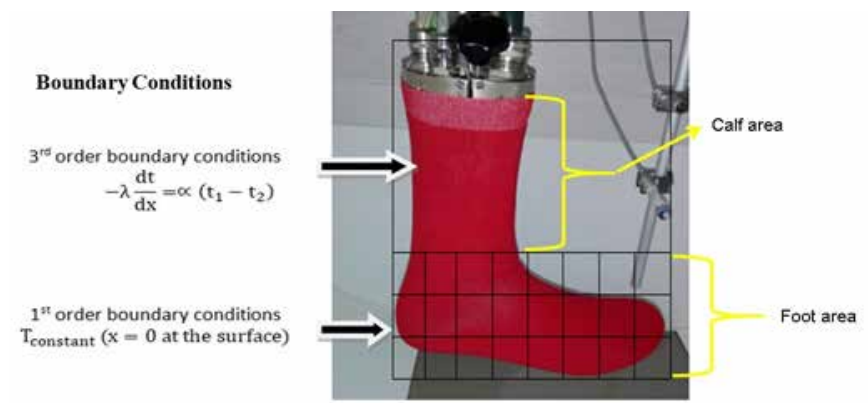

Figure 4. Worn sock situation inside the shoe.

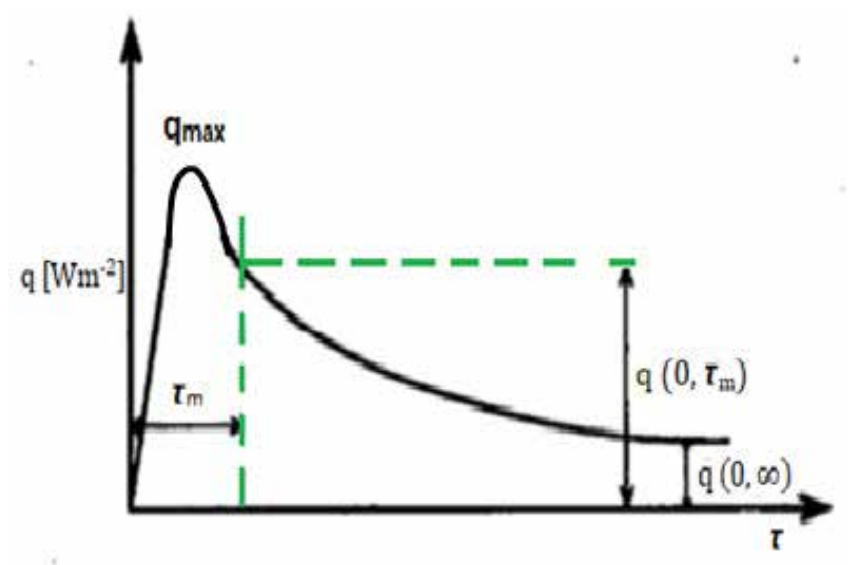

Figure 5. Time dependence heat flow after contact [44].

enables fast measurement of both steady-state and transientstate thermal properties, are shown in (Figure 5). This diagram demonstrated the maximum, $\mathrm{q}_{\max }$; dynamic (transient), $\mathrm{q}_{\mathrm{dyn}}$; and heat flow, $\mathrm{q}_{\text {steady }}$.

Steady-state heat flow has been shown by Eq. (11).

$\mathrm{q}_{\text {steady }}=\frac{\mathrm{t}_{1}-\mathrm{t}_{2}}{\mathrm{R}_{\mathrm{ct}}}$

Thermal resistance $\left(\mathrm{m}^{2} \cdot \mathrm{K} \cdot \mathrm{W}^{-1}\right)$ is used to express the heat insulation properties of the fabric. Thermal resistance of textiles is affected by fiber conductivity, fabric porosity, and fabric structure. It is also a function of fabric thickness, as shown by Eq. (12).

$\mathrm{R}_{\mathrm{ct}}=\frac{\mathrm{h}}{\lambda}$

\subsection{Thermal conductivity and filling coefficient calculations}

An average thermal conductivity for different fibers (within socks) at different moisture levels will be calculated as per Eq. (13).

Average Thermal Conductivity $\left(\lambda_{\text {wet Polymer }}\right)=\left(\frac{\mathrm{F}_{\mathrm{w}} \cdot \lambda_{\mathrm{W}}+\mathrm{F}_{\mathrm{fib}} \cdot \lambda_{\mathrm{fib}}+\mathrm{F}_{\mathrm{fib} 2} \lambda_{\mathrm{fib} 2}+\cdots}{\mathrm{F}_{\mathrm{w}}+\mathrm{F}_{\mathrm{fib}}+\mathrm{F}_{\mathrm{fib}}+\cdots}\right)$

where $F_{w}=$ water filling coefficient; $F_{\text {fib1 }}=1$ st-fiber filling coefficient; $F_{\text {fib2 }}=$ 2nd-fiber filling coefficient; $I_{w}=$ water thermal conductivity; $I_{\text {fib1 }}=1$ st-fiber thermal conductivity; and $I_{\text {fib2 }}=2$ ndfiber thermal conductivity. Filling coefficients for water, fiber, wet polymer, and the air are calculated as per steps given in Table 2.

Air filling coefficient $\left(\mathrm{F}_{\mathrm{a}}\right)$ is calculated as per Eq. (14).

Air filling coefficient $\left(\mathrm{F}_{\mathrm{a}}\right)=1-\left(\mathrm{F}_{\mathrm{w}}+\mathrm{F}_{\mathrm{fib}}\right)$

Filling coefficient for wet polymer will be calculated as per Eq. (15). This value will be used as input in all above models for measurement of thermal resistance in wet states.

Wet Polymer filling coefficient $\left(\mathrm{F}_{\text {wet polymer }}\right)=\mathrm{F}_{\mathrm{w}}+\mathrm{F}_{\text {fib }}$ 
Table 2. Filling coefficients.

\begin{tabular}{|c|c|c|}
\hline Measurement & $\mathbf{F}_{\mathrm{w}}=$ water filling coefficient & $\mathbf{F}_{\text {fib }}=$ fiber filling coefficient \\
\hline Moisture content & $\%$ & gram \\
\hline Mass & gram & $\mathrm{m}^{2}$ \\
\hline Area & $\mathrm{m}^{2}$ & $\frac{\mathrm{gram}}{\mathrm{m}^{2}}$ \\
\hline Areal density & $\frac{\mathrm{gram}}{\mathrm{m}^{2}}$ & $\frac{\text { Areal density }}{\text { Thickness }\left(\mathrm{kg} \cdot \mathrm{m}^{-3}\right)}$ \\
\hline Volumetric density & $\frac{\text { Areal density }}{\text { Fabric thickness }\left(\mathrm{kg} \cdot \mathrm{m}^{-3}\right)}$ & $\frac{\text { Volumetric density }}{\text { Fibre density }}$ \\
\hline Filling coefficient & Volumetric density & Water density \\
\hline
\end{tabular}

Table 3. Different fibers' properties.

\begin{tabular}{|c|c|c|}
\hline Fiber name & Density $\left(\mathbf{k g} \cdot \mathbf{~ m}^{-\mathbf{3}}\right)$ & Thermal conductivity $\left.\mathbf{( W} \cdot \mathbf{m}^{\mathbf{- 1}} \cdot \mathbf{K}^{\mathbf{- 1}}\right)$ \\
\hline Cotton & 1,540 & $0.50[46]$ \\
\hline Viscose & 1,530 & $0.50[22,45,46]$ \\
\hline Polyester & 1,360 & $0.40[45]$ \\
\hline
\end{tabular}

Thermal conductivity of water and air are taken as 0.600 and $0.026\left(\mathrm{~W} \cdot \mathrm{m}^{-1} \cdot \mathrm{K}^{-1}\right)$, respectively, while the density of water is $1,000\left(\mathrm{~kg} \cdot \mathrm{m}^{-3}\right)$. Different values were found for the thermal conductivity of textile fibers. However, the following values of density [45] and thermal conductivity have been taken for different fibers in this study; these are given in Table 3.

\subsection{Validation of the models}

Validation of the theoretical models is done by comparing results $(x)$ with results obtained by experiments $(y)$ for a set of parallel determinations. If both methods (theoretical and experimental) lead to same results, then the dependence of $y$ on $x$ is linear ( $y$ $=\beta_{1} x+\beta_{2}$ ) with zero intercept $\beta_{2}=0$ and unit slope $\beta_{1}=1$. This validation is done by the joint confidence region for intercept and slope because estimators are correlated. Assumptions for this composite inference will be :

1. Null hypothesis $H_{0}: \beta_{2}=0$ and $\beta_{1}=1$

2. Alternative hypothesis $H_{1}: \beta_{2} \neq 0$ and $\beta_{1} \neq 1$.

3. Level of significance: $\propto=0.05$

4. Test statistics:

$$
\mathrm{F}_{1}=\frac{\left(\mathrm{RSC}_{1}-\mathrm{RSC}\right)(\mathrm{n}-\mathrm{m})}{\operatorname{RSCq}}
$$

5. Critical region:
6. Check the value from table for Fisher-Snedecor F-distribution $\mathrm{F}_{0.95}(\mathrm{~m}, \mathrm{n}-\mathrm{m})$.

\section{Conclusion:}

If the calculated value as per Eq. (16) is less than the critical value, then accept the null hypothesis $H_{0}: \beta_{2}=0$ and $\beta_{1}=1$. It means intercept and slope are not significantly different from 0 and 1, respectively, at a 95\% confidence level. A simultaneous test of the composite hypothesis confirmed that a new laboratory method (by theoretical model) is in agreement with the results of a standard one (experimental). Further, if the calculated value is higher than the critical, then alternative hypothesis $H_{1}: b_{2}{ }^{1} 0$ and $b_{1}{ }^{1} 1$ will be accepted with the conclusion that theoretical model results are not in agreement with the experimental results [47].

\section{Results and discussions}

\subsection{Socks porosity by model and MCT}

Volume porosity (with and without extension) was determined by a semi-empirical approach as per Eq. (8) and fabric areal density and thickness need to be determined experimentally. Figure 6 shows the final (from the top, wales, and course views) images of all the tested socks scanned by MCT scanner (SkyScan 1272) as 2D and converted into 3D using NRecon. A sample size of $5 \times 5 \mathrm{~mm}$ has been used for scanning these images. 


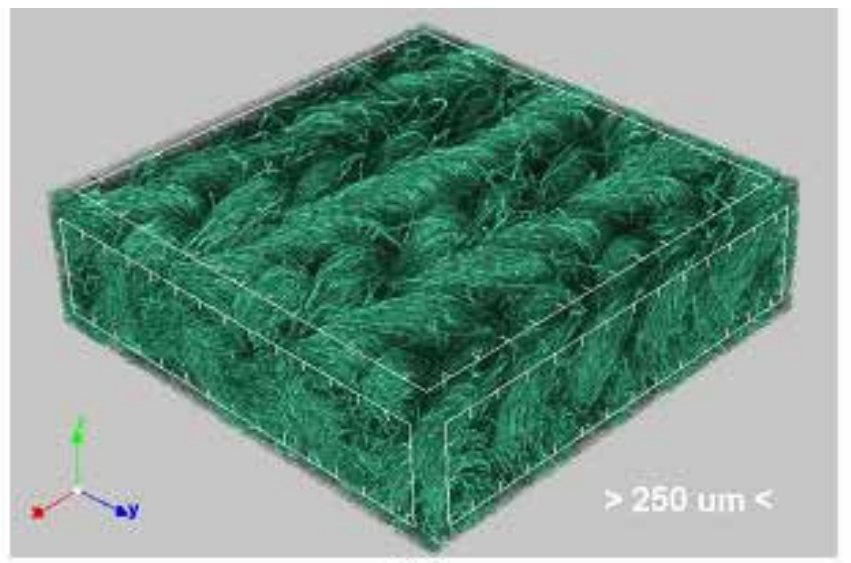

P1

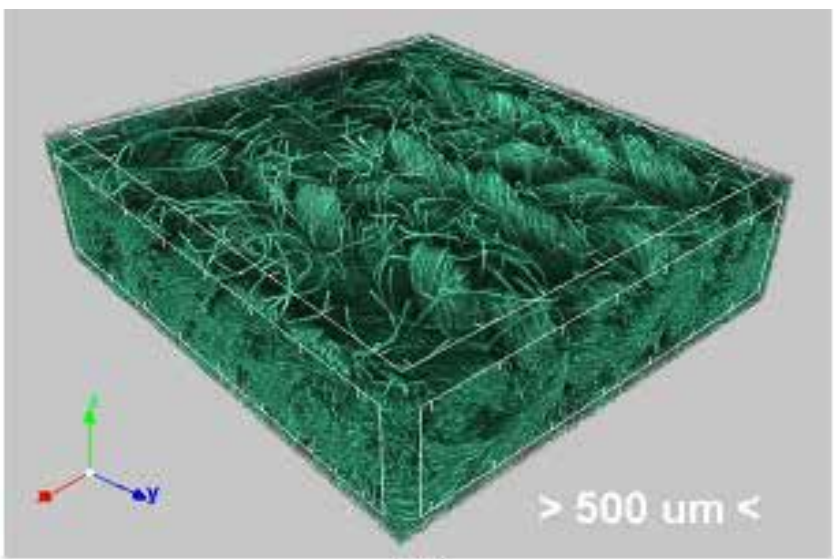

P2

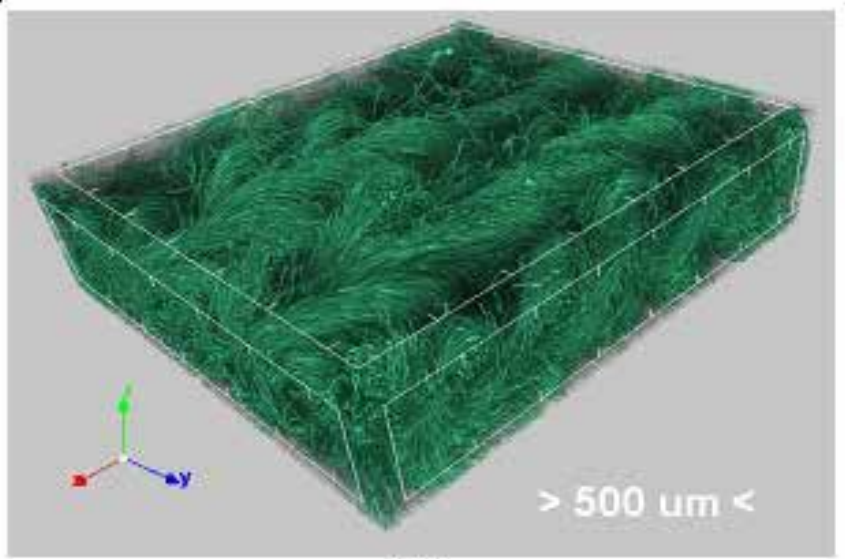

P3

Figure 6. 2D scanned images conversion into 3D images by using NRecon.

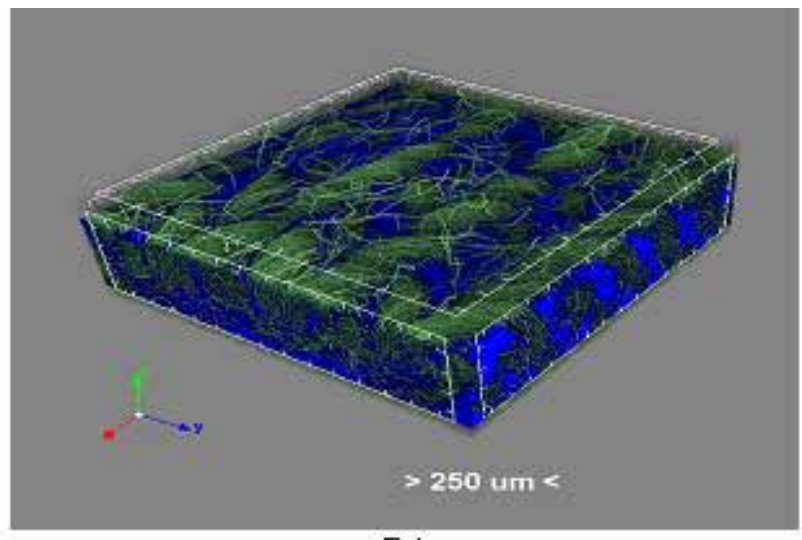

P1

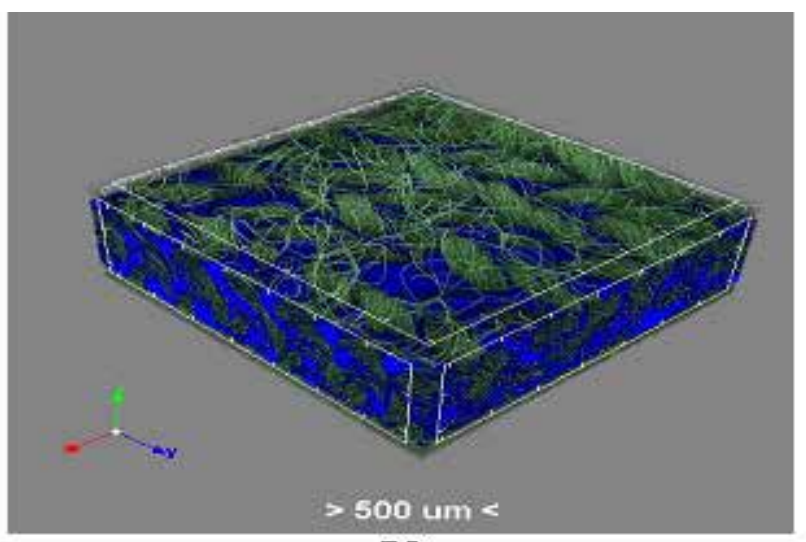

P2

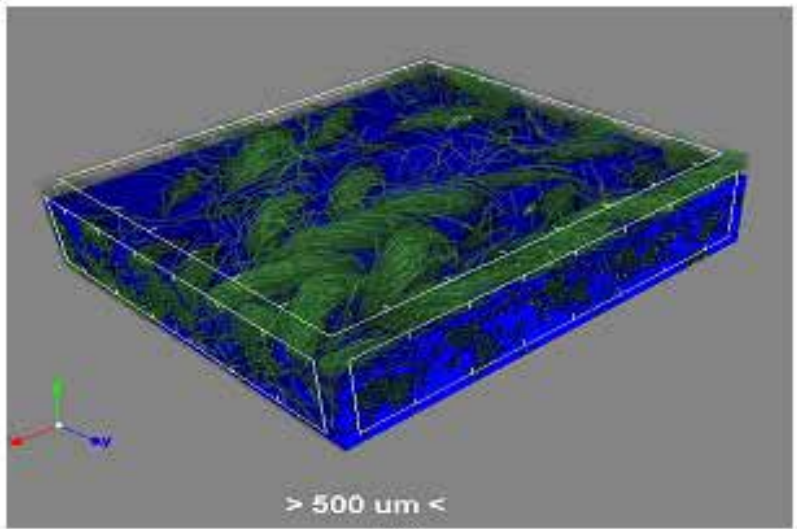

P3

Figure 7. Color coded images by CTVox. 


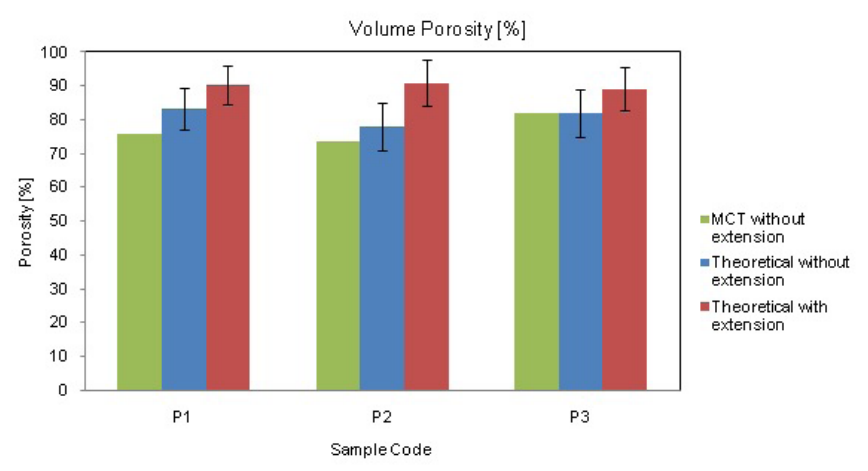

Figure 8. Volume porosity ( $\mathrm{MCT}$ vs. theoretical). $\mathrm{MCT}$, microtomography

For porosity quantification, distribution of the pores, and pore thickness, the above images were analyzed by using software recommended by the manufacturer (BRUKER), which is CTAn. The color coded images (Figure 7) were generated by CTVox by using the data provided by CTAn. The measurement of the $3 \mathrm{D}$ pore thickness is referred to as "sphere-fitting" and this thickness is considered as the diameter of the largest enclosed sphere [48].

The results of the volume porosity demonstrated that extended socks have higher porosity (Figure 8 ). This increase in the porosity was also reported by Abdolmaleki et al. at different extension levels for loose knitted fabrics [49]. Porosity falls in the range of $78 \%$ and $90 \%$ without and with extension, respectively. Guidoin et al. stated that knitted fabrics' porosity lies between $67 \%$ and $84 \%$ and even $90 \%$ is not uncommon [40]. Extension causes an increase in the pore size (space between loops) of the fabric and decreases the fabric thickness. It leads to a decrease in the volume of the fiber (solid part) and increases the volume of air corresponding to porosity. Porosity measured by MCT is in agreement with theoretical porosity (without extension) at a 95\% confidence level for all the socks. Thus, the thermal resistance model's prediction in the next sections is based on this porosity model. This comparison is logical and it further validated that the used model for the calculation of porosity is correct. The difference is in the range of $(0.1400-4.3715 \%)$ for all the socks except $\mathrm{P} 1$. The value of $7.4256 \%$ lower porosity is measured by MCT with respect to the predicted value, which is close to the difference observed by Doczyova et al. - i.e., $6 \%$ during porosity comparison of knitted structures [50].

\subsection{Effect of moisture content on heat transfer}

Figures 9,11 , and 13 clearly demonstrate that as the moisture (\%) increases, heat transfer also increases, irrespective of sock fiber composition. For all the models, the input thermal conductivity and filling coefficients were measured in wet polymer at different moisture levels. The correlation between experimental and predicted models was checked by coefficient of determination $\left(R^{2}\right)$. The values of coefficient of determination (Figures 10, 12, and 14) for all the three modified models (ME2, Schuhmeister, and Militky) showed that these models could make reasonable predictions of heat transfer in the dry as well as the wet condition at different moisture levels for all the major fiber blends used for socks. Coefficient of determination falls between 0.78 and 0.90 for all the samples.

\subsection{Assumptions for theoretical models}

Following are the assumptions made for the development of theoretical models for the prediction of heat transfer in the wet state:

- Fabric thickness assumed as constant.

- No Free convection (as Rayleigh Number < 1,000).

- The difference between the temperatures on both surfaces of the fabric 1st-order boundary conditions is considered constant.

- To simplify the model, fiber filling coefficient is assumed as constant.

- Air and water filling coefficients are variable.

- Fiber (polymer) and water filling coefficients are combined as wet polymer filling coefficient.

- Values for thermal conductivity of wet polymer in relation to water and fibers are combined as per their volume.

- No dimensional changes occurred at different moisture levels as tested in extended state.

- Fabric areal density and thickness are measured in the extended state.

\section{- Alambeta's thickness is considered.}

\subsubsection{Effect of moisture content on cotton socks (P1)}

The predicted and experimental heat transfer by conduction of $\mathrm{P} 1$ (cotton $80 \%$, polyester $18.20 \%$, and elastane $1.8 \%$ ) at various moisture levels is given in Figure 9. All the three, namely, Maxwell-modified, Militky-modified, and Schuhmeister models have the best prediction at different moisture levels for the P1 sample. Militky-modified, Schuhmeister-modified, and ME-2-modified models have $R^{2}$ values of $0.8776,0.8766$, and 0.8586 , respectively, as shown in Figure 10 . The heat loss is increasing with the increase of moisture level (Figure 9). About $50 \%$ increase in the heat transfer is observed at $30 \%$ moisture content. This increase is uniform till $20 \%$ moisture content, and then a rapid rise is observed between $20 \%$ and $30 \%$ moisture content. This trend is evident in Figure 9 (green square legends). Overall, Schuhmeister has the highest prediction due to $67 \%$ consideration of thermal conduction in series followed by the Militky-modified model. This means that as the portion of series in consideration decreases, thermal conductivity increases and further the result is in line with previous investigations of fiber alignment in series that has 2-3 times lower thermal conductivity than parallel [23, 51]. The findings are in accordance with the findings of Wang et al. [33]. They have predicted the thermal conductivity with respect to 


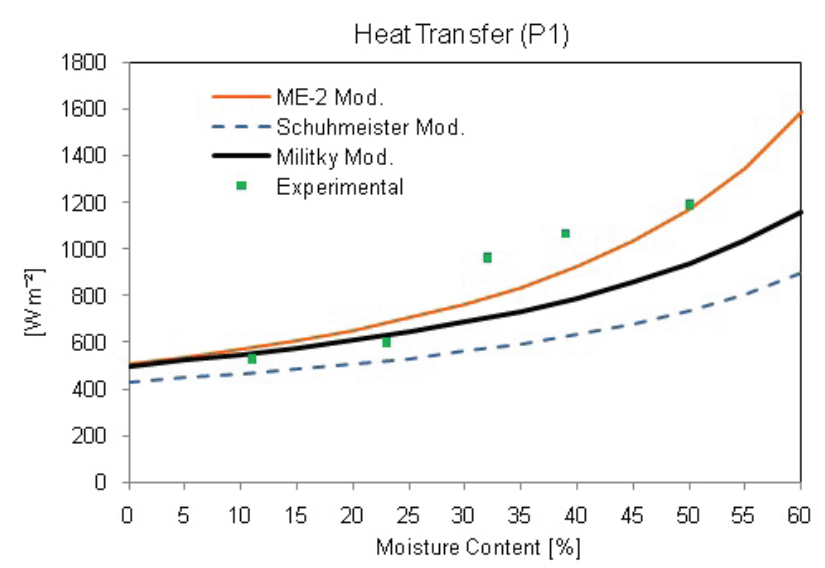

Figure 9. Predicted and experimental heat transfer: $\mathrm{P} 1$ (cotton $80 \%$, polyester $18.20 \%$, and elastane $1.8 \%$ ). ME-2, Maxwell-Eucken2.

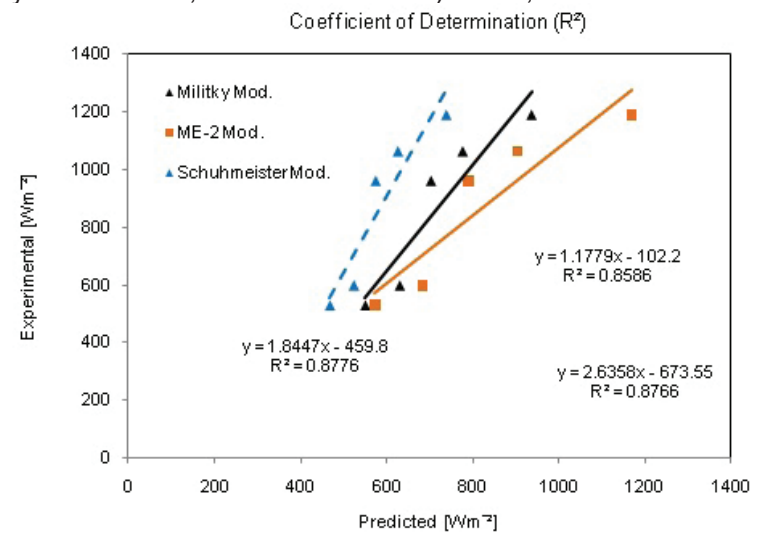

Figure 10. Coefficient of determination: $\mathrm{P} 1$ (cotton $80 \%$, polyester $18.20 \%$, and elastane 1.8\%). ME-2, Maxwell-Eucken2.

porosity by using different combinations and models, i.e., ME1, ME-2, series, parallel, EMT, series + parallel, ME-1 + ME-2, etc. According to their findings, the series model has the lowest thermal conductivity, followed by ME-2, while the parallel model has the highest prediction. Reddy and Karthikeyan [52] also have the same findings during their study for predicting the thermal conductivity of frozen and unfrozen food materials.

Validation of the theoretical models is done by comparing the results $(x)$ with results obtained by experiments $(y)$ for a set of parallel determinations. This validation is done by joint confidence region. On substitution into Eq. (16):

$$
F_{1}=\frac{(64352.20-47848.71)(5-2)}{(47848.71)(2)}=0.5174
$$

In the case of ME-2-modified model, $\left(F_{1}=0.5174\right)$ is lesser than the quantile of the Fisher-Snedecor F-distribution $F_{0.95}$ $(2,3)=9.5521$, so the null hypothesis $H_{0}$ cannot be rejected. It means the predicted heat transfer with the ME-2-modified model is not significantly different from the experimental results. Similarly, on substitution into Eq. (16) for Militky-modified model, we obtain:

$$
\mathrm{F}_{1}=\frac{(213993.64-43828.60)(5-2)}{(43828.60)(2)}=5.8238
$$

In Militky-modified model, $\left(F_{1}=5.8238\right)$ is lesser than the quantile of the Fisher-Snedecor F-distribution $\mathrm{F}_{0.95}(2,3)=9.5521$, so the null hypothesis $\mathrm{H}_{0}$ cannot be rejected. Again, it is verified that the predicted heat transfer with the Militky-modified model is not significantly different from the experimental results. On substitution into Eq. (16), for composite confidence region validation with Schuhmeister-modified model, we obtain:

$$
F_{1}=\frac{(558180.92-41763.19)(5-2)}{(41763.19)(2)}=18.5481
$$

In Schuhmeister-modified model, $\left(F_{1}=18.5481\right)$ is greater than the quantile of the Fisher-Snedecor F-distribution $\mathrm{F}_{0.95}(2$, $3)=9.5521$, so the null hypothesis $H_{0}$ cannot be accepted. It means that the predicted heat transfer with the Schuhmeistermodified model is significantly different from the experimental results.

\subsubsection{Effect of moisture content on viscose socks (P2)}

In the case of P2 sock (viscose $81.08 \%$, polyester $17.22 \%$, and elastane $1.77 \%$ ), Militky-modified model has the best prediction at $11.45 \%$ and $19.50 \%$ moisture levels, as shown in (Figure 11 ). ME-2 modified has a better heat transfer prediction at 30.30 ,

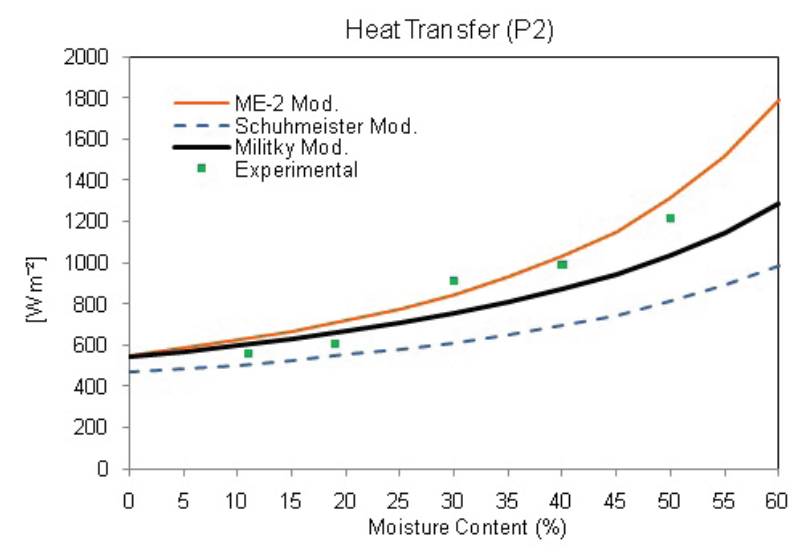

Figure 11. Predicted and experimental heat transfer: P2 (viscose $81.08 \%$, polyester $17.22 \%$, and elastane $1.77 \%$ ). ME-2, MaxwellEucken2.

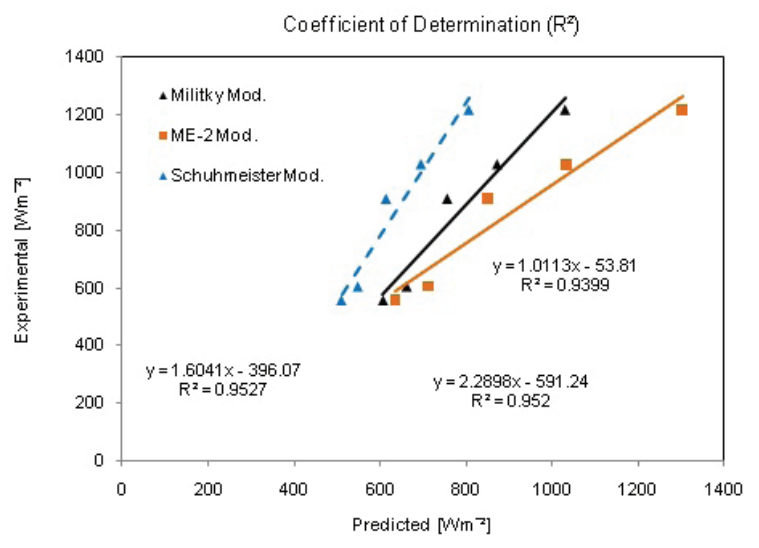

Figure 12. Coefficient of determination: P2 (viscose $81.08 \%$, polyester $17.22 \%$, and elastane 1.77\%). ME-2, Maxwell-Eucken2. 
$40.17 \%$, and $49.80 \%$ moisture levels. All three models have a reasonable prediction with $\mathrm{R}^{2}>0.93$, as shown in (Figure 12). Similar to the $\mathrm{P} 1$ sample, a rapid increase in the heat transfer with the increased moisture content is also observed, between $20 \%$ and $30 \%$ moisture content. This increase is in agreement with Naka and Kamata's study and close to the value reported by Mangat, i.e., $70 \%$ [27, 53]. Schuhmeister-modified model has the highest prediction followed by Militky-modified and ME-2-modified models at all the moisture levels. Over and over again lowest to the highest prediction of heat transfer order by different models has verified the findings of Finck [51], Bogaty et al. [23], Wang et al. [33], and Reddy [52]. From these studies, it has been established that series alignment has predicted the lowest thermal conductivity followed by ME-2; combinations of ME-2, ME-1, EMT, series, and parallel; EMT; ME-1; and parallel.

The values of composite confidence region for slope and intercept at $95 \%$ confidence level validated all the theoretical models except Schuhmeister-modified model, as calculated value $F_{1}=35.5029$ is higher than the critical value $F_{0.95}$ (2, $3)=9.5521$. This means that the heat transfer prediction with Schuhmeister-modified model is not significantly correct with respect to experimental results. As per acceptance of the null hypothesis $\mathrm{H}_{0}$, ME-2-modified model is validated as having lower $F_{1}$, i.e., 0.7598 than the critical value 9.5521. In case of Militky-modified model, $\left(F_{1}=7.3972\right)$ is lower than the quantile of the Fisher-Snedecor F-distribution $\mathrm{F}_{0.95}(2,3)=9.5521$, so the null hypothesis $\mathrm{H}_{0}$ cannot be rejected. On substitution in to Eq. (16):

$F_{1}=\frac{(28287.09-18776.27)(5-2)}{(18776.27)(2)}=0.7598$

$F_{1}$ for Militky-modified model:

$F_{1}=\frac{(87628.75-14773.51)(5-2)}{(14773.51)(2)}=7.3972$

$F_{1}$ for Schuhmeister-modified model:

$$
\mathrm{F}_{1}=\frac{(369795.92-14990.54)(5-2)}{(14990.54)(2)}=35.5029
$$

\subsubsection{Effect of moisture content on polyester socks (P3)}

Figure 13 depicts theoretical and experimental thermal resistances of P3 socks (polyester 98.38\% and elastane $1.62 \%)$ at various moisture levels. Militky-modified, Schuhmeister-modified, and ME-2-modified models have $\mathrm{R}^{2}$ values $0.8425,0.841$, and 0.7671 respectively (Figure 14). The increase in the heat transfer is slower and uniform between
$5-10 \%$ and $20-50 \%$ moisture content levels. However, this rise $(42 \%)$ is fast between $10 \%$ and $20 \%$ moisture content, as evident from experimental green square legends (Figure 13). Unlike $P 1$ and $P 2,50 \%$ of the heat transfer increase in $P 3$ is observed at $50 \%$ moisture content due to the hydrophobic nature of polyester. Once more Schuhmeister-modified model has a higher prediction at all the moisture levels except $5 \%$ and $10 \%$ moisture content. It has predicted $0.5-2$ times lower thermal conductivity. This is in accord with Mao and Russel's study [54]. They have observed 0.5-3 times lower thermal conductivity prediction for $100 \%$ polyester spacer fabric with Schuhmeister's model. They have not incorporated moisture content. Even then their predictions are very high with respect to experiments.

As per the values of the constructed confidence region for slope and intercept at 95\% confidence level, all the theoretical models except Schuhmeister-modified model have been validated. It means the intercepts $\left(\beta_{2}\right)$ and slopes $\left(\beta_{1}\right)$ are not significantly different from 0 and 1 , respectively. So, the heat transfer prediction with ME-2 and Militky-modified models is not significantly different with respect to experimental results for sample P3. Calculated values of $F_{1}$ also justify that the ME-2modified model has top prediction among all others followed

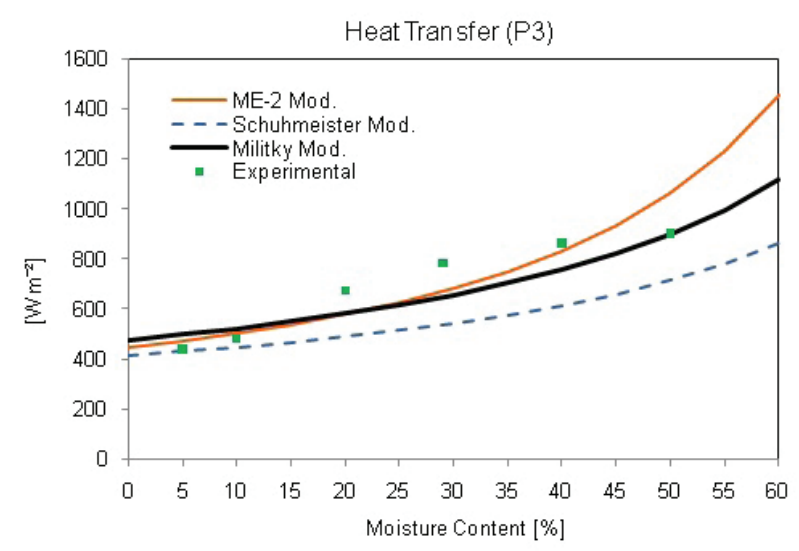

Figure 13. Predicted and experimental heat transfer: P3 (polyester $98.38 \%$ and elastane 1.62\%). ME-2, Maxwell-Eucken2.

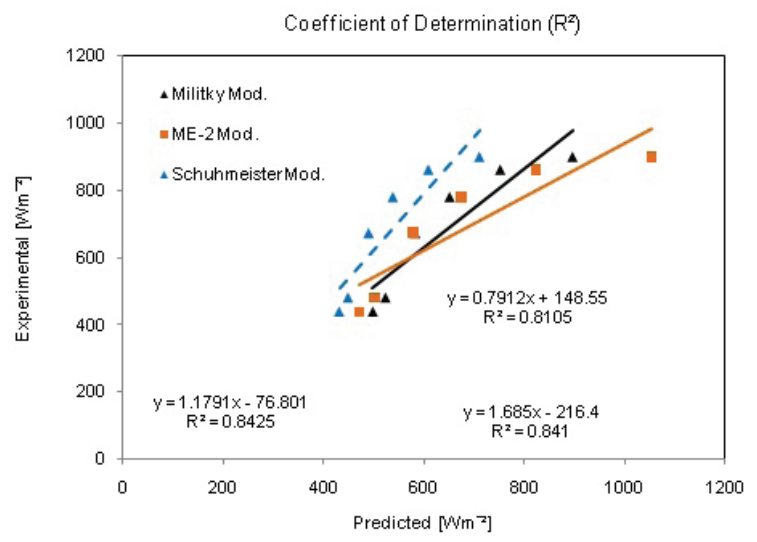

Figure 14. Coefficient of determination: P3 (polyester $98.38 \%$ and elastane 1.62\%). ME-2, Maxwell-Eucken2. 
by Militky-modified and Schuhmeister-modified models. To summarize, ME-2-modified model has the better forecast for sample P3 than both other models. Test statistics (calculated $F_{1}$ ) values are $0.6071,0.8773$, and 10.9260 for ME-2-, Militky-, and Schuhmeister-modified models, respectively, against the critical value of the Fisher-Snedecor F-distribution $F_{0.95}$ (2, $4)=6.9443 . F_{1}$ is calculated for ME-2 on substitution in to Eq. (16):

$$
\begin{aligned}
& \mathrm{F}_{1}=\frac{(46842.2-35934.25)(6-2)}{(35934.25)(2)} \quad=0.6071 \\
& \mathrm{~F}_{1} \text { for Militky modified: }
\end{aligned}
$$

$$
\mathrm{F}_{1}=\frac{(42987.81-29880.57)(6-2)}{(29880.57)(2)} \quad=0.8773
$$

$F_{1}$ for Schuhmeister modified:

$$
F_{1}=\frac{(194926.93-30160.37)(6-2)}{(30160.37)(2)}=10.9260
$$

\section{CONCLUSION}

A semi-empirical approach was used to model the heat transfer prediction of plain knitted socks in the wet state. This work focuses on the heat transfer prediction of socks in the wet state. The effects of fiber dimensions, orientation, and yarn hairiness were not taken into account. Both theoretical porosity and experimental for socks were calculated, but the heat transfer prediction is based on theoretical results. Image processing and analysis were used to obtain data on the porous structure of fabrics. Validation of the models has been done through the coefficient of determination $\left(R^{2}\right)$ and inference statistics, i.e., hypothesizing slope $=1$ and intercept $=0$ at $95 \%$ confidence interval.

By adopting this new approach of feeding the wet polymer filling coefficient and the thermal conductivity instead of dry polymers, different models can provide a justified prediction of heat transfer under wet conditions as well. All the models have a reasonable coefficient of determination, i.e., $\mathrm{R}^{2}$ range is in between 0.76 and $\sim 0.95$ for all the sock samples at different moisture levels. However, as far as the validation through hypothesis, i.e., slope $=1$ and intercept $=0$ is concerned; Schuhmeister-modified model could not qualify for all the socks. The polymer filling coefficient remains constant while water and air filling coefficients are changing with the variation of moisture that leads to changing the thermal conductivity. A higher value of moisture causes an increase in the heat transfer. A $50 \%$ increase in heat transfer was observed at $30 \%$ moisture content in all the samples, except P3 (polyester) socks. We hope that this study has uncovered many worthy avenues for future investigations. The inquisitive readers will no doubt have ideas of their own, but the following are some suggestions for research of possible interest:

- This study was conducted by assuming thickness and GSM as constant. A separate study could be planned to identify the effect of swelling on the thickness, especially in hydrophilic fabrics.

- Future studies could be planned for examining other types of fabrics and mathematical models by adopting this approach.

- Shoes could be included with the addition of more boundary conditions.

\section{ACKNOWLEDGMENTS}

This work is funded by Technical University of Liberec, Czech Republic, by SGS-2020 under Project no. 21410.

\section{References}

[1] Woo, S. S., Shalev, I., Barker, R. L. (1994). Heat and moisture transfer through nonwoven fabrics: Part l: Heat transfer. Textile Research Journal, 64(3), 149-162.

[2] Kawabata, S. (1986). Measurement of anisotropic thermal conductivity of single fiber. Sen'i Kikai Gakkaishi (Journal of the Textile Machinery Society of Japan), 39(12), T184-T186.

[3] Bhattacharjee, D., Kothari, V. K. (2009). Heat transfer through woven textiles. International Journal of Heat and Mass Transfer, 52(7-8), 2155-2160.

[4] Boughattas, A., Benltoufa, S., Hes, L., Musaddaq, A., Fayala, F. (2018). Thermo-physiological properties of woven structures in wet state. Industria Textila, 69, 298303.

[5] Wang, F., Lai, D., Shi, W., Fu, M. (2017). Effects of fabric thickness and material on apparent 'wet'conductive thermal resistance of knitted fabric 'skin'on sweating manikins. Journal of Thermal Biology, 70, 69-76.

[6] Oglakcioglu, N., Marmarali, A. (2010). Thermal comfort properties of cotton knitted fabrics in dry and wet states. Tekst ve Konfeksiyon, 20(3), 213-217.

[7] Chen, Y. S., Fan, J., Zhang, W. (2003). Clothing thermal insulation during sweating. Textile Research Journal, 73(2), 152-157.

[8] Kuklane, K., Holmér, I. (1998). Effect of sweating on insulation of footwear. International Journal of Occupational Safety and Ergonomics, 4(2), 123-136.

[9] Kuklane, K. (2009). Protection of feet in cold exposure. Industrial Health, 47(3), 242-253.

[10] Fogarty, A. L., Barlett, R., Ventenat, V., Havenith, G. (2006). Regional foot sweat rates during a 65-minute uphill walk with a backpack. 2006-2007.

[11] Taylor, N. A., Caldwell, J. N., Mekjavic, I. B. (2006). The sweating foot: Local differences in sweat secretion during exercise-induced hyperthermia. Aviation, Space, and Environmental Medicine, 77(10), 1020-1027. 
[12] Kuklane, K., Gavhed, D., Fredriksson, K. (2001). A field study in dairy farms: Thermal condition of feet. International Journal of Industrial Ergonomics, 27(6), 367-373.

[13] West, A. M., Tarrier, J., Hodder, S., Havenith, G. (2019). Sweat distribution and perceived wetness across the human foot: The effect of shoes and exercise intensity. Ergonomics, 62(11), 1450-1461.

[14] Young, A. J., Roberts, D. E., Scott, D. P., Cook, J. E., Mays, M. Z., et al. (1992). Sustaining health and performance in the cold: A pocket guide to environmental medicine aspects of cold-weather operations. Army Research Inst of Environmental Medicine Natick MA.

[15] Cleland, A. C. (1990). Food refrigeration processes. Elsevier applied science.

[16] Cleland, A. C., Earle, R. L. (1977). A comparison of analytical and numerical methods of predicting the freezing times of foods. Journal of Food Science, 42(5), 1390-1395.

[17] Mangat, A. E., Bajzik, V., Lubos, H. E. S., Mazari, F. B. (2015). The use of artificial neural networks to estimate thermal resistance of knitted fabrics. Tekstil ve Konfeksiyon, 25(4), 304-312.

[18] Kanat, Z. E., Özdil, N. (2018). Application of artificial neural network (ANN) for the prediction of thermal resistance of knitted fabrics at different moisture content. The Journal of the Textile Institute, 109(9), 1247-1253.

[19] Akyol, U., Erhan Akan, A., Durak, A. (2015). Simulation and thermodynamic analysis of a hot-air textile drying process. The Journal of the Textile Institute, 106(3), 260-274.

[20] Qian, X., Fan, J. (2006). Prediction of clothing thermal insulation and moisture vapour resistance of the clothed body walking in wind. The Annals of Occupational Hygiene, 50(8), 833-842.

[21] Schuhmeister, J. Ber. (1877). K Akad Wien (Math-Naturw Klasse) 76, 283.

[22] Baxter, S. T. (1946). The thermal conductivity of textiles. Proceedings of the Physical Society, 58(1), 105.

[23] Bogaty, H., Hollies, N. R., Harris, M. (1957). Some thermal properties of fabrics: part I: The effect of fiber arrangement. Textile Research Journal, 27(6), 445-449.

[24] Militký, J., Becker, C. (2011). Selected topics of textile and material Science. Select Topics of Textile and Material Science, 404

[25] Hollies, R. S., Bogaty, H. (1965). Some thermal properties of fabrics: part II: The influence of water content. Textile Research Journal, 35(2), 187-190.

[26] Mangat, M. M., Hes, L. (2014). Thermal resistance of denim fabric under dynamic moist conditions and its investigational confirmation. Fibres \& Textiles in Eastern Europe, 22, 101-105.

[27] Mangat, M. M., Hes, L., Bajzík, V. (2015). Thermal resistance models of selected fabrics in wet state and their experimental verification. Textile Research Journal, 85(2), 200-210.

[28] Mansoor, T., Hes, L., Bajzik, V., Norman, M. T. (2020). Novel method on thermal resistance prediction and thermo-physiological comfort of socks in a wet state. Textile Research Journal, 90(17-18), 1987-2006.
[29] Mansoor, T., Hes, L., Bajzik, V. (2020). A new approach for thermal resistance prediction of different composition plain socks in wet state (Part 2). Autex Research Journal, 1.

[30] Maxwell, J. C. (1954). A treatise on electricity and magnetism. New York: Dover.

[31]Eucken, A. (1940). Allgemeine gesetzmäßigkeiten für das wärmeleitvermögen verschiedener stoffarten und aggregatzustände. Forsch auf dem Gebiet des Ingenieurwesens A, 11(1), 6-20.

[32] Brailsford, A. D., Major, K. G. (1964). The thermal conductivity of aggregates of several phases, including porous materials. British Journal of Applied Physics, 15(3), 313.

[33] Wang, J., Carson, J. K., North, M. F., Cleland, D. J. (2006). A new approach to modelling the effective thermal conductivity of heterogeneous materials. International Journal of Heat and Mass Transfer, 49(17-18), 3075-3083.

[34] Carson, J. K. (2002). Prediction of the thermal conductivity of porous foods: a thesis submitted in partial fulfilment of the requirements for the degree of Doctor of Philosophy in Food Engineering, Massey University, Palmerston North, New Zealand.

[35] Mansoor, T., Siddique, H. F., Ali, A., Komarkova, P., Havelka, A., et al. (2018). Wrinkle free plaited knitted fabrics without pre-heat setting. The Journal of the Textile Institute, 109(3), 307-311.

[36] Mansoor, T., Hes, L., Skenderi, Z., Siddique, H. F., Hussain, $S$. , et al. (2019). Effect of preheat setting process on heat, mass and air transfer in plain socks. The Journal of Textile Institute, 110(2), 159-170.

[37] Yoon, H. N., Buckley, A. (1984). Improved comfort polyester: Part I: Transport properties and thermal comfort of polyester/cotton blend fabrics. Textile Research Journal, 54(5), 289-298.

[38] Bories, S., Mojtabi, A., Prat, M., Quintard, M. (1995). Transferts de chaleur dans les milieux poreux. Ed. Techniques Ingénieur.

[39] Dubois, A. (1999). Porosite des tissus: Correlations entre les methodes de determination de la permeabilite a l'air. Eurédia.

[40] Guidoin, R., King, M., Marceau, D., Cardou, A., De La Faye, D., et al. (1987). Textile arterial prostheses: Is water permeability equivalent to porosity? Journal of Biomedical Materials Research, 21(1), 65-87.

[41] Hsieh, Y. L. (1995). Liquid transport in fabric structures. Textile Research Journal, 65(5), 299-307.

[42] Dyck, V. (1998). Desktop X-ray microscopy and microtomography. Journal of Microscopy, 191(2), 151-158.

[43] Pressure measuring device for medical compression and support stockings (Salzman, Group Switzerland), https:// www.swiss/astic.ch/files/Druckmessgeraete/MST-MK V-EN_SP_JP_CN-2014-4p.pdf.

[44] Hes, L., Dolezal, I. (1989). New method and equipment for measuring thermal properties of textiles. Sen'i Kikai Gakkaishi (Journal of the Textile Machinery Society of Japan), 42(8), T124-T128.

[45] Wiley-VCH (ed). (2008). Ullmann's Fibers, 2 Volumes. Wiley, https://books.google.cz/books?id=R9c8wgEACAAJ. 
[46] Bobeth, W. (1993). Thermisches Verhalten. In: Textile Faserstoffe. Springer, pp. 253-284.

[47] Meloun, M., Militky, J. (2011). Statistical data analysis: A practical guide. Woodhead Publishing, Limited. doi: 10.1533/9780857097200.

[48] Visualization of local thickness in 3D (Bruker Micro CT Academ). (2014). 1, 2-3.

[49] Abdolmaleki, S., Jeddi, A. A. A., Amani, M. (2012). Estimation on the $3 D$ porosity of plain knitted fabric under uniaxial extension. Fibers and Polymers, 13(4), 535-541.

[50] Doczyova, K., Glombikova, V., Komarkova, P. (2014). Application of microtomography in textile metrology. Tekstilec, 57(1).
[51] Finck, J. L. (1930). Mechanism of heat flow in fibrous materials. Bureau of Standards Journal of Research, 5(5), 973-984.

[52] Reddy, K. S., Karthikeyan, P. (2010). Combinatory models for predicting the effective thermal conductivity of frozen and unfrozen food materials. Advances in Mechanical Engineering, 2, 901376.

[53] Naka, S., Kamata, Y. (1977). Thermal conductivity of wet fabrics. Journal of the Textile Machinery Society of Japan, 23(4), 114-119.

[54] Mao, N., Russell, S. J. (2007). The thermal insulation properties of spacer fabrics with a mechanically integrated wool fiber surface. Textile Research Journal, 77(12), 914922. 